\title{
Basic Studies on Chemopreventive Properties of Quercetin and Curcumin and Other Plant-origin Compounds in Ovarian Cancer Cells - A Mini-review
}

Radosław Kujawski ${ }^{1 *}$, Justyna Baraniak ${ }^{2}$, Marcin Ożarowski ${ }^{2,3}$, Małgorzata Kujawska ${ }^{4}$, Magdalena Borowska1, Malgorzata Kania ${ }^{2}$, Joanna Bartkowiak-

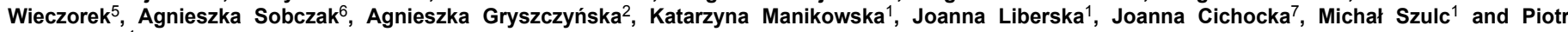
Ruszkowski ${ }^{1}$

${ }^{1}$ Department of Pharmacology, Poznan University of Medical Sciences, Poland

${ }^{2}$ Department of Pharmacology and Phytochemistry, Institute of Natural Fibers and Medicinal Plants, Poland

${ }^{3}$ Department of Pharmaceutical Botany and Plant Biotechnology, Poznan University of Medical Sciences, Poland

${ }^{4}$ Department of Toxicology, Poznan University of Medical Sciences, Poland

${ }^{5}$ Department of Clinical Pharmacy and Biopharmacy, Poznan University of Medical Sciences, Poland

${ }^{6}$ Department of Pharmaceutical Chemistry, Poznan University of Medical Sciences, Poland

${ }^{7}$ Wielkopolska Centre for Advanced Technologies (WCAT), Adam Mickiewicz University in Poznan, Poland

*Corresponding author: Radosław Kujawski, Department of Pharmacology, Poznan University of Medical Science, Rokietnicka 5a Str., 60-806 Poznań, Poland, Tel: +480618547262; E-mail: radkuj@ump.edu.pl

Received date: March 17, 2017; Accepted date: May 10, 2017; Published date: May 17, 2017

Copyright: ( 2017 Kujawski R, et al. This is an open-access article distributed under the terms of the Creative Commons Attribution License, which permits unrestricted use, distribution, and reproduction in any medium, provided the original author and source are credited.

\begin{abstract}
Despite the increasing number of studies on the molecular actions of quercetin and curcumin, their anticancer efficacy, safety and molecular aspects of chemopreventive action in the ovarian cancer prophylaxis or treatment and also their potential in the sensitization to cytostatics used in the clinical practice remains still not clearly understood.

Based on basic studies we have summarized evidences for inhibitory activities of several often studied plantorigin bio-active compounds (mostly quercetin and curcumin) against ovarian cancer cells proliferation, their mechanisms of action as well as their strong potential to sensitization of ovarian cancer cells to the presence of several platinum-based cytostatics - cisplatin and oxaliplatin. Up to date only several dietary, clinical (cohort and case-control) studies evaluating the association of some flavonoids (mostly nonisoflavones) and its subgroup components consumption and ovarian cancer risk were already performed. According to the researchers, there has been no association between ovarian cancer risk and total nonisoflavone flavonoids intake. There is a still an insufficient amount of data designed to explain the effect of quercetin or curcumin (alone or together) on ovarian cancer development and/or its chemotherapy. Obtained results provide limited support for an association between nonisoflavone flavonoids intake and ovarian cancer risk, therefore there is a need for further and more accurate studies to be confirmed. We are of the opinion that this paper will contribute to a better understanding of the molecular basis for positive interactions between concomitant usage of quercetin or curcumin with above-mentioned cytostatics and other bio-active agents. This work may also contribute to an increase in the number of preclinical studies or other clinical, dietary trials using these or other phenolic / alkaloid, plant-origin constituents in order to investigate efficiency and safety of pharmacotherapy of ovarian cancer patients.
\end{abstract}

Keywords: Ovarian cancer; Chemoprevention; Flavonoids; Quercetin; Curcumin; Cisplatin

Abbreviations: A2780 (wild - type): A2780 (cisR) (cisplatinresistant) and A2780 (ZD0473R) (ZD0473-resistant)-Ovarian Cancer Cells; CAT: Catalase; CDDP: Cis-diammine Dichloro Platinum; CHOP: CCAAT/Enhancer-binding protein Homologous Protein; cytoc: Cytochrome c; DNA-PK: DNA-dependent Protein Kinase; DR5: Cell Death Receptor; EFO-27: Ovarian Cancer Cell Line; ENDOG: Endonuclease G; ERS: Endoplasmic Reticulum-Stress; GPx: Glutathione Peroxidase; IP3: Inositol, 1,4,5-Trisphosphate; MMP-2 and MMP-9: Two Metallo Proteinases; MPEG-PCL: Nanoformulated Quercetin; OVCAR: Human Ovarian Carcinoma Cell Line; PI: 1Phosphatidylinositol; PIP Kinase: 1-Phosphatidylinositol 4-Phosphate 5-Kinase; Q: Quercetin, 3,3',4',5-7-Pentahydroxyflavone; RF: Resistance Factor; ROS: Reactive Oxygen Species; SCOV-3-Human Ovary Cancer Cell Line; SOD 1: Superoxide Dismutase; TQ:
Thymoquinone: TRAIL: Apoptosis-Inducing Ligand; Type II EBS: Type II Estrogen Binding Sites; UCP2: Uncoupling Protein 2

\section{Introduction}

Ovarian cancer is the most leading cause of death from gynecological cancer in the Western world [1-3]. This may be due to the absence of early symptoms which causes the disease. In approximately two-thirds of patients the disease spreads beyond the ovaries [4] resulting in poor prognosis of ovarian cancer stems mainly from the high percentage of cases diagnosed at an advanced stage. Although most patients with advanced ovarian cancer respond to firstline chemotherapy, $80 \%$ of the patients ultimately succumb to death due to recurrence [5].

New strategies to improve clinical response and to reduce toxicity of cancer therapy focus nowadays on chemoprevention, which hopes to 
Citation: Kujawski R, Baraniak J, Ozarowski M, Kujawska M, Borowska M, et al. (2017) Basic Studies on Chemopreventive Properties of Quercetin and Curcumin and Other Plant-origin Compounds in Ovarian Cancer Cells - A Mini-review. Altern Integr Med 6: 238. doi: $10.4172 / 2327-5162.1000238$

Page 2 of 10

identify substances that can suppress cancer transformation [6] According to the current state of knowledge chemoprevention includes using agents that affect cell-cycle progression and apoptosis, signal transduction, oncogene activation, polyamine metabolism, angiogenesis, gap junctional intercellular communication, and more $[6,7]$. According to guidelines for cancer prevention published by the American Cancer Society Guidelines, one of the key lifestyle factors thought to modify cancer risk is a diet, especially that rich in plantorigin compounds [8-11]. Although nowadays natural therapies are being more and more often considered by physicians to be used even in cancer patients, together with targeted therapies, still little is known about their interaction with conventional chemotherapeutic agents. Numerous studies indicate that chemopreventive phytochemicals with phenolic structure, for example flavonoids or curcuminoids, possessing antiproliferative and antioxidant properties that can overcome problems of drug resistance and nonspecific toxicity towards normal cells, by reducing the side-effects that are associated with chemotherapy $[10,12,13]$.

Flavonoids with several functions in pathological processes of cancer are polyphenolic compounds with a basic benzo- $\gamma$-pyrone structure being widely distributed in all foods of plant origin such as fruit, vegetable, tea and wine $[9,14,15]$. Some studies indicate that the observed pharmacological activities of flavonoids on ovarian cancer may depend on their structure $[9,12]$. Based on the range and structural complexity, flavonoids can be categorized into six major subclasses: flavones, isoflavones, flavonols, flavanones, anthocyanidins and flavan-3-ols [11,16], among which flavones, isoflavones and flavonols are reported in the highest amounts of consumption in the human diet and have biological activity in ovarian cancer $[8,9,17,18]$.

One of the most abundant flavonol, identified in various types of vegetable [19-21], caper fruits [22], fruits [23], herbs (dill), some types of tea [24] and wine [25], being of the most extensively studied in this field is the quercetin $[11,26-28]$. Numerous studies have demonstrated that another plant-origin constituent-curcumin (a yellow substance belonging to the polyphenols superfamily; active component of turmeric, a common Indian spice, derived i.e. from the dried Curcuma longa rhizome) and its derivatives possess anti-oxidant, antiinflammatory and anti-cancerous activities $[29,30]$.

In this manuscript we aimed to summarized, based on basic studies, evidences of inhibitory activities against ovarian cancer cells proliferation of several plant-origin bio-active compounds, mainly quercetin and curcumin, described their cytotoxic potential when treated alone or with other phenolic or alkaloid substances, as well as their strong potential to sensitization of ovarian cancer cells to the presence of several cytostatics, mostly platinum-based ones. Only few experiments with quercetin and curcumin applied together on ovarian cancer cells were carried out so far.

Already published literature presents a number of experimental, pre-clinical results of in-vitro, in-vivo studies concerning the mechanism of action of quercetin and curcumin and their bio-active metabolites against ovarian cancer cells proliferation and/or in vivo tumor development. Although there have been published some reviews summarizing knowledge in this subject [31-34], in this paper we have presented more precise of dose-dependent in vitro, in vivo aspects of action of above mentioned plant origin bio-active compounds in relation to platinum-based cytostatics towards ovarian cancer.

\section{Methods}

We have done a review of in vitro and in vivo studies evaluating the correlation between the ability to inhibit ovarian cancer cells proliferation, defining the mechanisms of action of these bio-active compounds, administered alone, in combine treatment, in combination with other metabolites or two platinum-based cytostatics (cisplatin, oxaliplatin). For this purpose a systematic search for relevant publications was made using PubMed, Medline, Google Scholar databases. English and nonEnglish papers published up to February 2017 were screened using the following keywords "flavonoid", "quercetin", "curcumin", "ovarian cancer", "molecular", "platinum-based cytostatics", "cisplatin". Clinical (cohort or casecontrol studies) studies scanned based on their title, abstract, and their major aims, their full texts were excluded.

\section{Results}

The knowledge gained as a result of the above methodology is presented below.

\section{Chemoprotective activities in ovarian cancer cells of quercetin, alone or with cytostatics or other plant compounds}

Early in vitro study on OVCAR 433 ovarian cancer cell line demonstrated synergistic antiproliferative activity of quercetin (Q) with cisplatin (CDDP) acting through an interaction with type II estrogen binding sites (type II EBS). A dose-dependent growth inhibition (range of concentrations was $0.01 \mu \mathrm{M}$ to $2.5 \mu \mathrm{M}$ and 0.01 $\mu \mathrm{g} / \mathrm{ml}$ to $2.5 \mu \mathrm{g} / \mathrm{ml}$ for Q and CDDP, respectively) when administered separately, while their combination resulted in a synergistic action. Two other studied flavonoids as rutin (3-rhamnosyl-glucoside of quercetin) and hesperidin (3'-5-3-hydroxy-4-methoxyflavone) were ineffective, both alone and in combination with CDDP [35]. Another experiment showed the capability of quercetin to reversible dosedependent inhibition of cancer cells proliferation in the range of concentrations between $10 \mathrm{nM}$ to $10 \mu \mathrm{M}$, without such effect of rutin and hesperidin [35]. Moreover, a synergistic, dose-dependent inhibition of colony formation of cells from 4 primary ovarian tumors expressing type II EBS and reduction of hyperthermia $\left(42^{\circ} \mathrm{C}\right)$ effect in three out of four tumors analyzed was also observed in the case of quercetin $(0.1 \mu \mathrm{M}$ to $10 \mu \mathrm{M}$; $\max 10 \mu \mathrm{M})$, while rutin and hesperidin were ineffective in synergizing with hyperthermia [36]. Quercetin inhibited proliferation of human ovarian carcinoma OVCAR-5 cells (IC50 for growth inhibition=63 $\mu \mathrm{M}$; LC50 for cytotoxicity=17 $\mu \mathrm{M}$ ) via suppression of signal transduction activity by concentrationdependent declining in 1-phosphatidylinositol (PI) 4-kinase leading to an $80 \%$ decrease in PI kinase activity and a $65 \%$ decrease in the concentration of the second messenger, inositol 1,4,5-trisphosphate (IP3), closely correlated with its concentration change. PI-4 kinase is the first committed enzyme in the PI phosphorylation pathway of signal transduction leading to the production of the second messengers [37].

Studied flavonol acted synergistically also with one of the major soy isoflavones genistein, is a promising reagent for cancer chemoprevention and/or treatment [38-44] with minimal or no toxicity to nonmalignant human cells $[45,46]$ in ovarian carcinoma OVCAR- 5 cells causing i.e. arrests the cell cycle at G1 and S phase [37]. As the authors assumpted quercetin blocked the cell cycle at G1 and S phase boundary, while the second one attacked the cell cycle at G2 
Citation: Kujawski R, Baraniak J, Ozarowski M, Kujawska M, Borowska M, et al. (2017) Basic Studies on Chemopreventive Properties of Quercetin and Curcumin and Other Plant-origin Compounds in Ovarian Cancer Cells - A Mini-review. Altern Integr Med 6: 238. doi: $10.4172 / 2327-5162.1000238$

Page 3 of 10

and/or early $\mathrm{M}$ phase. In another experiment [47] both metabolites, as in the case by Prajda et al. [37], blocked the phosphatidylinositol conversion to IP3 signal transduction pathway, mainly by the inhibition of PI kinase (EC 2.7.1.67) and another member of the signaling route-1-phosphatidylinositol 4-phosphate 5-kinase (PIP kinase, EC 2.7.1.68), respectively. For these experiment conditions the IC50 values for quercetin and genistein (mean \pm SE) were as follows: $66 \pm 3.0$ and $32 \pm 2.5 \mu \mathrm{M}$; in clonogenic assays they were $15 \pm 1.2$ and 5 $\pm 0.5 \mu \mathrm{M}$, respectively. When such flavone was added to the cultures of OVCAR- 5 cells followed $8 \mathrm{~h}$ later by genistein, synergism was still observed in growth inhibition [47]. This flavonoid acted also synergistically with antiviral ribavirin in OVCAR-5 cells (as well as in human myeloma 8226 cell line). Additionally, quercetin inhibited of PI-4 kinase activity as well as the activity of another studied enzymePIP-5 kinase (EC 2.7.1.68) in cells. The observed IC50 and LC50 values in growth inhibition for ribavirin were of 35 and $23 \mu \mathrm{M}$, respectively. A synergistic antiproliferative action was observed when quercetin was added $24 \mathrm{~h}$ after ribavirin and in combined treatment of ribavirin with studied flavonol [48]. An inhibition of activity of PI kinase by quercetin in ovarian cancer cells was also observed by Weber et al. [49], as well as a dose-dependent inhibition of PIP kinase in the case of genistein, while tiazofurin lowered the guanosine tri-phosphorane (GTP) concentration required for phosphoinositide-specific phospholipase C (PLC) protein. Combinations of tiazofurin with quercetin, tiazofurin with genistein, and quercetin with genistein yielded a synergistic kill of ovarian cancer cells [49].

An in vitro (A2780 and A2780cisR ovarian cancer cell lines) time (sequence)-dependent synergistic mechanism of action of quercetin and other bio-active metabolite-thymoquinone (TQ) with cytostatics such as cisplatin and oxaliplatin, was observed by Nessa et al. [50]. TQ is known antioxidant from a variety of biological activities including chemoprevention and inhibition of tumor growth [51]. It was demonstrated that although the oxaliplatin was the most active from all used compounds, among plant-derived metabolites, thymoquinone was the most active, with higher activity in the resistant cell line than in the parent cell line. Although these two phytochemicals were less active than both platinum cytostatics, they had resistance factor (RF) higher than the platinum drugs. RF is defined as the ratio of the concentration of the drug required for $50 \%$ cell kill in the resistant cell line to that in the parent cell line. The greatest synergism was observed when the phytochemicals were added first followed by platinum drug 2 $\mathrm{h}$ later and the least synergism was observed when the two compounds were administered as a bolus. Authors hypothesized that the addition of the plant-origin compounds $2 \mathrm{~h}$ before platinum drug may sensitize cancer cells to platinum action, thus offering a means of overcoming drug resistance [51].

Results by Gao et al. [52] with a novel form of nano-formulation of quercetin yielded a promising in vitro and in vivo antiproliferative effects. Such form of quercetin inhibited the growth of A2780S ovarian cancer cells on a dose dependent manner. In this experiment quercetin treatment induced the apoptosis of A2780S cells associated with activation of proteases essential in programmed cell death development-caspase-3 and caspase-9. The profile of other molecular markers, Mcl-1 and Bcl-2 proteins, has also changed causing their down regulation, also Bax upregulation and mitochondrial transmembrane potential change, suggesting an induction of apoptosis through the mitochondrial apoptotic pathway. Furthermore, an intravenous administration of such nanoformulated quercetin (MPEGPCL micelles) significantly suppressed the growth of established xenograft A2780S ovarian tumors through causing cancer cell apoptosis and inhibiting angiogenesis in vivo [52]. In another study [53] an analysis of cytotoxic potential of quercetin (with final concentrations: $0.1 ; 0.5 ; 1,5,10,50,100,500 \mu \mathrm{M}$ ) in a set of ovarian cancer cells: SCOV-3, EFO27, OVCAR-3, A2780P revealed a significantly increase of sensitivity of some of them to cisplatin and paclitaxel. In this study a similar sensitivity of studied ovarian cancer cells for quercetin was obtained (with IC50 values for OVCAR-3 cells $=42 \mu \mathrm{M}$; for $\mathrm{EFO} 27$ cells $=59 \mu \mathrm{M}$; for $\mathrm{A} 2780 \mathrm{P}$ cells $=70 \mu \mathrm{M}$; SCOV-3 cells $=90 \mu \mathrm{M})$. A treatment of cells with 1 and $5 \mu \mathrm{M}$ quercetin with those two cytostatics (in three concentrations marked as: $\left.\mathrm{K} 1=\left(10^{-1}\right) \times \mathrm{K} 2 ; \mathrm{K} 3=10 \times \mathrm{K} 2\right)$ caused a significant increase of sensitivity of all three cell line to paclitaxel, especially on SCOV-3 cell line which before the supplementation with quercetin was resistant to this drug. Also the sensitivity to cisplatin of OVCAR-3 and A278OP cells increased. Hence, results from this study revealed also a potential of analyzed flavonoid to overcome the chemoresistance of ovarian cancer cells to some cytostatics [53].

Catanzaro et al. [54] showed that among studied fifteen plant polyphenols, quercetin (as well as rhein and capsaicin) $(0.01 \mu \mathrm{M}$ to 100 $\mu \mathrm{M})$ was able to cause the arrest of the human ovarian carcinoma 2008 cells and their cisplatin (CDDP)-resistant subclones-C13 cells cycle, suggesting that such cell cycle regulatory proteins are possibly involved in their intracellular mechanism of action. This effect was more potent in $\mathrm{C} 13$ cisplatin (CDDP)-resistant cells. Furthermore, a dosedependent $(10 \mu \mathrm{M}$ to $50 \mu \mathrm{M})$ cytotoxic effects and cell cycle modulation of the quercetin in SKOV3 cancer cells and in its cisplatin (CDDP)-resistant counterpart (SKOV3/CDDP) cells was also observed in another experiment by Catanzaro et al. [55]. In this study evident changes in the distribution of cell cycle phases in the CDDP-resistant SKOV3/CDDP ovarian cell line caused by the presence of studied flavonoid and the significant decrease of the cyclin D1 expression in SKOV3 cells (probably linked with the G1/S phase alteration) were proved, but not in SKOV3/CDDP cells. Quercetin influenced also the G2/M phase of cell cycle, however without affecting the cyclin B1 levels (required for $\mathrm{G} 2 / \mathrm{M}$ phase) which indicates the involvement of other possible mechanisms [55].

Recently, an enhancement by quercetin $(50 \mu \mathrm{M}, 100 \mu \mathrm{M}, 200 \mu \mathrm{M})$ of apoptotic death of human ovarian cancer SKOV-3, OVCAR-3 and TOV-21G cells to the presence of the tumor necrosis factor-related apoptosis-inducing ligand (TRAIL) $(25 \mathrm{ng} / \mathrm{ml})$ through activation of JNK cellular signal transduction kinase, upregulation of a transcription factor CCAAT enhancer-binding protein (CEBP)) homologous protein (CHOP), induction of cell death receptor DR5, activated by TRAIL [56,57], was observed [58]. According to the authors, the combination of quercetin with TRAIL did not affected on DR5 receptor expression, ROS (important upstream signals required for the upregulation of death receptors; capable to induce CHOP expression) [59] mediated endoplasmic reticulum-stress (ERS) [58]. In this study a combined treatment of the cells with both TRAIL and quercetin showed significantly higher cell death compared to TRAIL or quercetin applied alone. The IC50 values for quercetin combined with or without TRAIL in ovarian cancer cells such as SKOV-3, OVCAR-3 and TOV-21G cells were found to be $222.1 \pm 5.64 \mu \mathrm{M} v s .153 .3 \pm 4.03$ $\mu \mathrm{M}, 217.2 \pm 4.89 \mu \mathrm{M}$ vs. $147.4 \pm 3.86 \mu \mathrm{M}$, and $237.6 \pm 6.07 \mu \mathrm{M}$ vs. $159.4 \pm 3.64 \mu \mathrm{M}$, respectively. However, $200 \mu \mathrm{M}$ quercetin did not significantly affect cell viability in normal ovarian cells (HOSE cells). Apoptosis in these three cell lines was induced at $14.85 \pm 2.93 \%, 11.99$ $\pm 2.33 \%$, and $12.67 \pm 2.61 \%$ by quercetin, at $9.42 \pm 1.75 \%, 8.53 \pm 1.21 \%$, and $10.82 \pm 2.01 \%$ by TRAIL, and at $36.42 \pm 5.04 \%, 30.34 \pm 4.54 \%$, and $33.29 \pm 5.28 \%$ by the combination of the two agents. In accordance 
Citation: Kujawski R, Baraniak J, Ozarowski M, Kujawska M, Borowska M, et al. (2017) Basic Studies on Chemopreventive Properties of Quercetin and Curcumin and Other Plant-origin Compounds in Ovarian Cancer Cells - A Mini-review. Altern Integr Med 6: 238. doi: $10.4172 / 2327-5162.1000238$

Page 4 of 10

with these results, activation of caspase- 3,8 , and 9 and PARP cleavage were significantly increased when the SKOV-3 cells were exposed to both, quercetin and TRAIL. These observations clearly indicated that quercetin was able to increase TRAIL-induced apoptosis in studied ovarian cancer cells. Analyzed flavonoid significantly affected mitochondrial membrane potential in SCOV-3 cells significantly increased the intracellular ROS levels and decreased the levels of $\mathrm{D \Psi m}$ in SKOV-3 cells in a dose-dependent manner. Thus, results by Yi et al. [58] strongly emphasized the role of ROS in the up-regulating of CHOP and enhancing the effects of TRAIL-induced apoptosis by quercetin. Furthermore, quercetin enhancement TRAIL mediated inhibition of tumor growth of human SKOV-3 xenograft was associated with induction of apoptosis, activation of caspase-3, CHOP and DR5. According to the authors all obtained results suggest that quercetin could be an attractive candidate for combined chemotherapy against cancer.

Results concordant to those obtained by Yi et al. [58] were observed in a study by Ren et al. [59]. In this study a time (after 24 or $48 \mathrm{~h}$ of treatment) and a dose-dependent manner $(0,0.12,0.23,0.47,0.94$, $1.88,3.75,7.5,15$ or $30 \mathrm{mg} / \mathrm{ml}$ ) inhibition of the proliferation of SKOV-3 cancer cells by quercetin occurred. Also an in vitro inhibition of cell cycle progression from G0/G1 to G2/M, cell apoptosis induction (analyzed by Hoechst staining and morphologically) and reduction of survivin protein level due the presence of this flavonol was also confirmed. In this study the strongest inhibitory effect on cell growth was observed following treatment with $30 \mathrm{mg} / \mathrm{ml}$ quercetin, when the inhibitory rate of cell proliferation reached peak value $58.72 \%$. The total apoptosis rate of the SKOV3 cells treated with $15 \mathrm{mg} / \mathrm{ml}$ quercetin was significantly higher than that of the control cells (33.62 \pm 1.17 vs. $7.13 \pm 0.92 \%, \mathrm{n}=6, \mathrm{P}<0.01)$. When the cells were treated with $30 \mathrm{mg} / \mathrm{ml}$ quercetin, the total apoptosis rate was $69.12 \pm 2.97 \%$, which was significantly higher than that of the low dose $(15 \mathrm{mg} / \mathrm{ml})$ of quercetin group and the control $(n=6, P<0.01)$. Further detailed analysis revealed that following treatment with quercetin the number of cells at G0/G1 phase was significantly increased, while the number of cells at $\mathrm{S}$ and G2/M phases was relatively decreased compared with the control group. It suggested therefore that quercetin can cause cell cycle arrest at the G1 phase for ovarian cancer SKOV3 cells, may prevent the cell cycle progression from G1 to $S$ phase and can induce cell apoptosis. Thus, these results clearly indicated that cell cycle arrest may be one of the important mechanisms underlying the quercetininduced inhibition of ovarian cancer SKOV3 cell growth, as well as quercetininduced cell apoptosis [59].

Results from another study by Yang et al. [60], similar to those obtained by Maciejczyk et al. [53] or Yi et al. [58] showed that quercetin pretreatment at a low dose may augment drug-resistant ovarian cancer cells for cisplatin chemotherapy by involving the endoplasmic reticulum-stress (ERS) proces via alternation of STAT3 kinase signaling (phosphorylation), a key player involved in ovarian cancer $[61,62]$, modulated by ERS [60]. In this study quercetin decreased the viability of both the $\mathrm{C}_{1} 3^{*}$ and P-ris cells in a dosedependent manner, with an IC50 value of approximately $100 \mu \mathrm{M}$ at 48 $\mathrm{h}$; the growth of both cell types could only be significantly inhibited with quercetin concentrations $>40 \mu \mathrm{M}$, with a negligible cytotoxicity in both cell types at a dose $20 \mu \mathrm{M}$. Furthermore, cisplatin treatment with quercetin pretreatment had the greatest inhibitory effect on cancer cell growth. Such pretreatment markedly potentiated the cytotoxicity of cisplatin in studied ovarian cancer cells, and the apoptotic behavior was due to the activation of caspase- 9 and caspase- 3 of the intrinsic pathway-it was observed that quercetin pretreatment rather than cisplatin alone significantly increased the levels of cleaved caspase-9, cleaved caspase- 3 and PARP proteins. Studied plant metabolite at a dose higher than $20 \mu \mathrm{M}$ had a greater impact on cisplatin cytotoxicity and this influence was dose dependent [60].

In a ovarian cancer xenograft mice quercetin $(40 \mathrm{mg} / \mathrm{kg}$; i.p.) enhanced the antitumor effect of cisplatin ( $3 \mathrm{mg} / \mathrm{kg}$; i.p.). Tumors from mice treated with cisplatin in combination with quercetin pretreatment had repressed STAT3 kinase phosphorylation, lower BCL-2 protein and higher apoptosis levels. The weekly intraperitoneal administration of cisplatin for 4 weeks only modestly reduced the tumor growth by $44.2 \%$, while its weekly treatment day after the 40 $\mathrm{mg} / \mathrm{kg}$ quercetin treatment remarkably decreased tumor growth by $89.6 \%$. Summarizing, Yang et al. [60] revealed a hitherto undescribed cellular response demonstrating that the quercetin pretreatment, involving the ERS process, may be a promising way to solve the systemic side effects and high incidence of resistance to cisplatin in ovarian cancer pharmacotherapy.

Although previous results indicating pro-apoptotic effect of mostly relatively high concentrations of quercetin $(40 \mu \mathrm{M}$ to $100 \mu \mathrm{M})$, in vitro (in human ovarian cancer $\mathrm{C} 13^{*}$ and SKOV3 cells) and in vivo results by $\mathrm{Li}$ et al. [63] have demonstrated that quercetin even at low concentrations may cause the attenuation of cisplatin and other antineoplastic agents (taxol, pirarubicin and 5-fluorouracil) therapeutic effects in ovarian cancer cells by reducing ROS damage. In this study the IC50 value in cisplatin-treated $\mathrm{C}_{13}{ }^{*}$ cells was approximately $80 \mu \mathrm{M}$ (IC50 $=78.8 \mu \mathrm{M}, 95 \% \mathrm{CI}: 72.9 \mu \mathrm{M}$ to $85.1 \mu \mathrm{M}$ ). It was shown that low concentrations of analyzed flavonoid $(20 \mu \mathrm{M})$, not high concentrations $(80 \mu \mathrm{M})$, antagonized the cytotoxic effects of cisplatin in $\mathrm{C} 13^{*}$ cells. It was done by increasing cell resistance to cisplatin in varying degrees; decreasing in numbers of apoptotic cells treated with cisplatin and 20 $\mu \mathrm{M}$ of quercetin than with cisplatin alone. High concentrations of quercetin had an additive effect with cisplatin. Similar to those results, treatment using other neoplastic drug taxol $(3 \mu \mathrm{M})$, pirarubicin $(3 \mathrm{nM})$ and 5 - Fu $(5 \mu \mathrm{M})$ in combination with quercetin (in a series of increasing doses) resulted in more cell resistance than treatment with three drugs alone. Quercetin at the $20 \mu \mathrm{M}$ concentration showed antiapoptotic effects against these three drugs. Studied flavonol showed also a low-concentration-specific protecting effect to ovarian cancer cells treated with 5-Fu, similar to the results obtained with cisplatin. In combination with taxol or pirarubicin, however, it maintained the effect of promoting cells survival against anticancer drugs even at relatively high concentrations $(80,100 \mu \mathrm{M})$. Further detailed analysis of quercetin influence on the oxidative injury of ovarian cancer cells caused by cisplatin revealed that low concentrations of quercetin were observed to suppress ROS-induced injury, reduce intracellular ROS level. It was shown, for example, that the quantities of both ROS: $\mathrm{cH} 2 \mathrm{AX}$ (a common marker of DNA damage) and 8hydroxydeoxyguanosine (8-OHdG; a marker of oxidative DNA stress) were much lower in the treatment group of $80 \mu \mathrm{M}$ cisplatin combined with the low concentration of quercetin $(20 \mu \mathrm{M})$ than the group of 80 $\mu \mathrm{M}$ cytostatic alone. Contrary to this, $80 \mu \mathrm{M}$ cisplatin with high concentration $(60 \mu \mathrm{M} ; 100 \mu \mathrm{M})$ of analyzed plant metabolite increased the intensity of fluorescence. Combination treatment with quercetin $(20 \mu \mathrm{M})$ had a more obvious decrease of $8-\mathrm{OHdG}$ than that of $\mathrm{cH} 2 \mathrm{AX}$, compared to cisplatin treatment alone $(36.40 \%$ and $19.33 \%$, respectively). Moreover, comparing to cells treated with vehicle control or cisplatin alone, treatment with an additional $20 \mu \mathrm{M}$ quercetin lead to a reduction in intracellular levels of ROS. Furthermore, low quercetin concentration caused increased expression of endogenous antioxidant enzymes transcripts (superoxide dismutase 1-SOD1, 
Citation: Kujawski R, Baraniak J, Ozarowski M, Kujawska M, Borowska M, et al. (2017) Basic Studies on Chemopreventive Properties of Quercetin and Curcumin and Other Plant-origin Compounds in Ovarian Cancer Cells - A Mini-review. Altern Integr Med 6: 238. doi: $10.4172 / 2327-5162.1000238$

Page 5 of 10

endonuclease G-ENDOG, cytochrome c-cyto-c, glutathione peroxidase-GPx, catalase-CAT and uncoupling protein 2-UCP2). Summarizing, obtained results suggested a ROS-mediated mechanism of action of quercetin attenuating anti-neoplastic drugs effects. Surprisingly, in an applied xenogeneic model (a nude mouse xenograft model injected with $\mathrm{C} 13^{*}$ cells), studied flavonol ( $40 \mathrm{mg} / \mathrm{kg}$; i.p.; daily) led to a substantial reduction of therapeutic efficacy of cisplatin. For example, it was found out that tumors from mice treated with cisplatin in combination with quercetin were approximately 1.8 times larger at day 30 than those treated with cisplatin alone $(\mathrm{P}<0.001)$. Evenmore, tumors treated with combination of quercetin and cisplatin $(72.53 \pm$ $7.33 \mathrm{mg}$ ) were significantly heavier than that treated with cytostatic alone $(41.47 \pm 6.72 \mathrm{mg}) \quad(\mathrm{P}<0.001)$. With this effect also an enhancement of the endogenous SOD1 enzyme expression and reduction of the ROS-induced damage in xenograft tumor tissue were observed. The SOD1 protein was highly overexpressed in tumors treated with quercetin or cisplatin with quercetin compared to tumors treated with vehicle or cisplatin alone [63]. Overall, data obtained by $\mathrm{Li}$ et al. indicated that administration of quercetin at low concentrations may antagonize the cytotoxic effects of anti-neoplastic drugs in studied ovarian cancer cells, and that this plant metabolite is able to decrease the levels of oxidative injury caused by cisplatin [63].

An induction of apoptosis of human ovarian carcinoma SKOV-3 and A2780 cells through activation of the extrinsic death receptors and intrinsic mitochondrial apoptotic pathways via modulation of expression levels of cleaved caspase-3 (as was shown in experiments by Yi et al. [58] or Yang et al. [60]) and induction of overexpression of miR-145 by quercetin was also confirmed by Zhou et al. [64]. These results are with the trend of studies indicating that some microRNAs, including the miR-145, are downregulated in ovarian cancer $[65,66]$, and that cancer cells growth inhibition caused by quercetin may be correlated with the modulation of several miRs expression of $[60,63$, $67,68]$.

Quercetin, among other eight studied compounds, was also able to inhibit OVCAR5, OVCAR3, TOV112D, CAOV3 ovarian cancer cells growth via induction of apoptosis and inhibition of the glycolytic pathway-by blocking five glycolysis pathway molecules-(glucose transporter 1 (GLUT1), hexokinase II (HKII), PFKFB3 (an isozyme; a component of fructose-2, 6-bisphosphate (Fru-2, 6-BP), an allosteric activator of 6-phosphofructo-1-kinase (PFK1) [69]), pyruvate dehydrogenase kinase 1 (PDHK1) and lactate dehydrogenase (LDH)) via an increased extracellular glucose and decreased lactate production, which was especially seen at low oxygen conditions. Variation in oxygen levels between $0.5 \%$ and $7 \%$ had a relatively small effect on the efficacy of the studied inhibitors. The IC50 values of quercetin for OVCAR5, TOV112D, OVCAR3, CAOV3 cells were 154, $94,21,240 \mu \mathrm{M}$, respectively [70]. The choice of glycolytic pathway enzymes analyzed in this study was due to the fact, that they are well substantiated and considered a 'hallmark' of advanced cancers [71]. The fact that cancer cells reduce their dependence on mitochondrial oxidative phosphorylation and are more reliant on glycolysis provides a wide range of potential targets for therapy. Targeting aerobic glycolysis is a promising strategy to preferentially kill cancer cells which are dependent on this pathway and in recent years multiple glycolytic inhibitors have been developed [72,73].

The above-described results were related so far to quercetin being a non-physically component of the plant extract. Wang et al. [74] demonstrated results of the influence of quercetin aglycone (and seven other flavonols: myricetin-3-galactoside, quercetin-3-galactoside, quercetin-3-glucoside, quercetin-3-xylopyranoside, quercetin-3arabinopyranosdie, quercetin-3-arabinofuranoside, quercetin-3rhamnopyranoside) as well as eleven member of A-type proanthocyanidins isolated from Vaccinium macrocarpon (American cranberry) against SKOV-3 and OVCAR-8 cancer cells. Two of them, quercetin aglycone and PAC DP-9, showed promising in vitro cytotoxic and anti-proliferative properties. Compared to quercetin glycosides, quercetin aglycone exhibited higher cytotoxicity against these cancer cell lines (IC50 $=83$ and $61 \mu \mathrm{g} / \mathrm{ml}$ for SKOV-3 and OVCAR-8 cells, respectively).

Both compounds strongly induced apoptosis led to caspase-3 activation and PARP deactivation, and increased sensitivity to cisplatin (concentrations of: quercetin aglycone $10 \mu \mathrm{g} / \mathrm{ml}$, cisplatin $=15 \mu \mathrm{g} / \mathrm{ml}$ or $60 \mu \mathrm{g} / \mathrm{ml}$; measurement after $12 \mathrm{~h}$ of cisplatin treatment). In addition, quercetin aglycone (and PAC DP-9) deactivated the MAPK-ERK kinases pathway, induced downregulation of: cyclin D1 kinase, DNAdependent protein kinase (DNA-PK) and the phospho-histone H3 proteins - often overexpressed in ovarian cancer cells.

Also this aglycone caused an upregulation of p21 protein, and the cell cycle progression arrest (G1/S-phase arrest in OVCAR-8 cells after the treatment for 24 and $48 \mathrm{~h}$ ). In conclusion, according to Wang et al. the integration of quercetin (and/or PAC DP-9) in ovarian cancer chemotherapy may improve outcomes. Moreover, among studied compounds quercetin aglycone induced cellular apoptotic events including cell cycle arrest and suppression of DNA repair pathways highlighted their potential as dietarily available therapeutic agents [74]. The quercetininduced apoptotic cell death correlated with several kinases phosphorylation was also proved in the study by Kim et al. [75] but in a different cell line model. In this study the presence of quercetin, detected in Rubus coreanus Miquel (RCM) extract, or other phenolic compound - an ellagic acid, caused an apoptosis of the doxorubicinresistant NCI/ADRRES ovarian cancer cells induced the phosphorylation of JNK and AKT kinase. The same effect was observed in the case of RCM extract, however, without the synergism with doxorubicin in reduction of cells viability [75].

An inhibition of proliferation of ovarian cancer cells by quercetin $(0$, 2.5, 5 and $10 \mu \mathrm{g} / \mathrm{ml}$; after 72 hours) was also observed by Choi et al. [76]. This study was performed not only on paclitaxel sensitive (SCOV-3) but also on SCOV-3/PAX (paclitaxel resistant) ovarian cancer cells as well. The action was compared to $80 \%$ methanolic extract of Rhus verniciflua Stokes (syn. Toxicodendron vernicifluum Stokes) (RVS) $(50,100,200$ and $500 \mu \mathrm{g} / \mathrm{ml})$ in which quercetin was present. In this study quercetin dose-depedently (more potent than fisetin alone) reduced cell growth. Other activities of quercetin, observed in the case of another analyzed flavonoid-butein, such as strong activation of cleavage of caspase- $9,-8,-3$, and PARP, reduction of AKT phosphorylation or SKOV-3/PAX cells arrest in sub-G1 phase, were not further examined [76].

Recent study by Ediriweera et al. [77] demonstrated also a cytotoxic potential of quercetin (and other three compounds) isolated from the chloroform extract of Mangifera zeylanica Hook.f. bark in ovarian epithelial cancer (SKOV-3), as well as in three other cancer cell lines triple negative breast cancer (MDA-MB-231), estrogen receptor positive breast cancer (MCF-7), and normal mammary epithelial (MCF-10A) cells. Quercetin was found to be cytotoxic to all three cancer cell lines examined in a dose dependent manner. IC50 values for quercetin at $24 \mathrm{~h}$ and $48 \mathrm{~h}$ for SKOV-3 cells were $170.18 \pm 3.92$, $109.9 \pm 2.64 \mathrm{mM}$, respectively. Also a DPPH free radical scavenging activity $(\mathrm{EC} 50=33.1 \pm 0.59 \mathrm{mM})$ of quercetin was shown [77]. 
Citation: Kujawski R, Baraniak J, Ozarowski M, Kujawska M, Borowska M, et al. (2017) Basic Studies on Chemopreventive Properties of Quercetin and Curcumin and Other Plant-origin Compounds in Ovarian Cancer Cells - A Mini-review. Altern Integr Med 6: 238. doi: $10.4172 / 2327-5162.1000238$

Page 6 of 10

Studies by Liu et al. [78] on human ovarian cancer (OC) CAOV3 cells and on primary OC cells provided evidences for a novel role of endoplasmic reticulum (ER-responsible for protein translocation, protein folding, and protein post-translational modifications) stress (perturbations in ER function triggering the unfolded protein response (UPR), a tightly orchestrated collection of intracellular signal transduction reactions designed to restore protein homeostasis; triggering the apoptotic machinery ultimately leading to cell death under severe or chronic stress conditions) as, as authors described, a "double edge sword" participating in quercetin-induced apoptosis [78]. In this study quercetin ( $40 \mu \mathrm{M} ; 80 \mu \mathrm{M}$ for $48 \mathrm{~h})$ irreversibly evoked ER stress to involve in mitochondria apoptosis pathway via the p-STAT3/ Bcl-2 axis in OC cell lines and in primary OC cells. The quercetininduced ER stress activated protective autophagy concomitantly by activating the p-STAT3/Bcl-2 axis in this process. Moreover, the autophagy scavenger-3-methyladenine (3MA) was shown to enhance quercetin's anticancer effects in an ovarian cancer mice xenograft model $\left(5 \times 10^{-6}\right)$ of human ovarian cancer CAOV3 cells in $100 \mathrm{ul}$ volume of PBS injected s.c. into the right supra scapula region of mice). For this purpose following in vivo experimental conditions were carried out: 5 days after tumor implantation the mice were treated i.p. with $80 \mathrm{mg} / \mathrm{kg}$ of quercetin twice a week; $30 \mathrm{mg} / \mathrm{kg} 3 \mathrm{MA}$ twice a week; a combination of $30 \mathrm{mg} / \mathrm{kg} 3 \mathrm{MA}$ and $80 \mathrm{mg} / \mathrm{kg}$ of quercetin twice a week; or a vehicle control injected with the same volume of saline for 4 weeks [78]. The results of this study are consistent with the trend of predecessor studies $[56,60,77]$ showing that quercetin has the potential to induce protective autophagy in cancer cells through AKT-mTOR and hypoxia-induced factor $1 \alpha$ signaling $[79,80]$ and in this way to induce autophagy in ovarian cancer cells [81].

There is also a growing number of studies justifying the use of plantderived bio-active metabolites, especially polyphenols, in cancerogenesis prevention/inhibition by applying them in combinations with other micronutrients for achieving pleiotropic effects [34,82-89]. This is especially interesting when one considers the fact of their poor bioavailability in the human body. In addition, their interactions with other natural compounds in a diet may hinder or complicate consistency of their efficacy [90]. According to the supporters of this strategy these compounds, which are abundant from dietary sources, show great promise in cancer treatment, especially considering their potential safe use. Due to their ability to modulate multiple biological mechanisms involved in cancer initiation/ progression, they may offer more comprehensive therapeutic effects than single drugs [34]. It is believed that the bioavailability, as well as chemopreventive or even therapeutic properties of these nutrients, may be enhanced and expanded in combination therapies that include natural compounds of the same or different chemical class. Thus, a combinations of i.e. polyphenols with micronutrients essential for maintaining integrity and stability of extracellular matrix and therefore provides the opportunity to expand the preventive/therapeutic effect of their anti-cancer action. They include targeting complementary metabolic pathways important in curtailing cancer invasion and metastasis. Therefore, specifically designed combinations of several bio-active compounds, especially polyphenols or combinations of polyphenols with other natural agents aimed at defined biological targets will expand metabolic effects of constituents of such mixtures in controlled and reproducible ways. In addition, proper combinations of micronutrients enable use of lower doses of individual components without compromising their efficacy, rather than expanding the scope of cellular mechanisms affected. According to researchers this approach may open up a possibility of developing more effective anticancer strategies [34].

In the context of the above information such anti-cancer potential of quercetin with EGCG (at concentrations between 0 and $1000 \mu \mathrm{g} / \mathrm{ml}$ ) and in combination with the micronutrient mixture against ovarian cancer using two different cell lines (ES-2 or A-2780) or in athymic female mice inoculated with ES-2 cells was demonstrated by Roomi et al. [82,91-93]. Studied micronutrient mixture EPQ (containing the following nutrients in the relative amounts indicated: vitamin $C$ (as ascorbic acid and as $\mathrm{Mg}$, Ca ascorbates, and ascorbyl palmitate) 700 mg; L-lysine $1000 \mathrm{mg}$; L-proline $750 \mathrm{mg}$; L-arginine $500 \mathrm{mg}$; $\mathrm{N}$-acetyl cysteine $200 \mathrm{mg}$; standardized green tea extract ( $80 \%$ polyphenol) 1000 $\mathrm{mg}$; quercetin as quercetin dihydrate, from Saphora japonica $50 \mathrm{mg}$; selenium $30 \mathrm{~g}$; copper $2 \mathrm{mg}$; manganese $1 \mathrm{mg}$ ) was investigated and the proposed mechanism of action was via modulation of expression of two metalloproteinases ( (MMP-2 and MMP-9) (these MMPs are prognostic for survival and metastatic potential in ovarian cancer [94-96]. Athymic female mice inoculated with ES-2 ovarian cancer cells showed that dietary intake of EPQ $(0.5 \%, w / w)$ inhibited weight and burden of tumors by $59.2 \%(\mathrm{p}<0.0001)$ and $59.7 \%(\mathrm{p}<0.0001)$, respectively [91]. In a study with mice injected (i.p.) with A-2780 cancer cells, control mice developed large ovarian tumors, whereas five out of six mice in the EPQ group developed no tumors, and one, only a small tumor-tumor growth was suppressed by EPQ by $87 \%(\mathrm{p}<0.0001)$ [92]. In vitro analyzes proved also the antiproliferative potential of EPQ. EPQ exhibited 35\% toxicity over the control in ES-2 cells [91] and $80 \%$ in A-2780 cells [92] at $1000 \mathrm{~g} / \mathrm{mL}$ concentration. ES-2 cells demonstrated only MMP-2, with and without PMA, which was inhibited by EPQ in a dose dependent fashion, with near total inhibition at $1000 \mathrm{~g} / \mathrm{ml}$ [91]. A-2780 cells demonstrated only MMP-9 expression, which EPQ inhibited in a dose dependent fashion, with virtual total block at $250 \mathrm{~g} / \mathrm{mL}$ concentration [92], while the migration of ES-2 cells were inhibited in a dose dependent manner with total block of invasion and migration at $500 \mathrm{~g} / \mathrm{ml}$ [91]. However, it is difficult to indicate which compound of nutrient mixture examined the higher anticancer activity, a $1000 \mathrm{mg}$ quercetin dihydrate concentration may suggest its crucial role in the EPQ action, however such hypothesis along with their putative action in a synergistic manner requires further evaluation [91,93]. Nevertheless, these studies clearly give credit for the usage of natural health compounds widely presented in human diet to prevent or inhibit ovaries carcinogenesis [91-93].

\section{Studies on curcumin alone or with quercetin and other compounds in ovarian cancer cells}

A potential of curcumin and quercetin for enhancing cisplatin sensitivity in two ovarian cancer cell lines: SKOV3 and CAOV3 (less susceptible to cisplatin, with a higher IL-6 protein production) was observed by Chan et al. [51]. Both compounds inhibited the growth of SKOV3 and CAOV3 cells in a dose-dependent and similar manner (quercetin at $10 \mu \mathrm{M}$ to $20 \mu \mathrm{M}$; curcumin at $5 \mu \mathrm{M}$ to $15 \mu \mathrm{M}$ ). Such inhibition was attained by day 2-3 after drug treatment and persisted thereafter (in max. 5 days experiment duration). They increased the sensitivity of CAOV3 and SKOV3 cells to cisplatin $(2 \mu \mathrm{g} / \mathrm{ml})$ (the concentrations of quercetin were as follows: $0 ; 5 ; 10 ; 15 ; 20 \mu \mathrm{M}$, while curcumin were as follows: $0 ; 2.5 ; 5.10 ; 15 \mu \mathrm{M}$ ). This effect of sensitization was obtained when the compounds were added $24 \mathrm{~h}$ before or simultaneously with cisplatin. In an applied experimental model the high IL-6 protein producing CAOV3 cells were less 
Citation: Kujawski R, Baraniak J, Ozarowski M, Kujawska M, Borowska M, et al. (2017) Basic Studies on Chemopreventive Properties of Quercetin and Curcumin and Other Plant-origin Compounds in Ovarian Cancer Cells - A Mini-review. Altern Integr Med 6: 238. doi: $10.4172 / 2327-5162.1000238$

Page 7 of 10

susceptible to cisplatin-induced cytotoxicity than the low producer SKOV3 cell line. The survival rate of CAOV3 cells at 2 days after treatment with $1 \mathrm{mg} / \mathrm{ml}$ of cisplatin was $87 \%$, whereas that of SKOV3 was at $45 \%$ (IC50 values for the two cell lines were $6.1 \mathrm{mg} / \mathrm{ml}$ and 0.9 $\mathrm{mg} / \mathrm{ml}$, respectively). According to authors these difference resembles the levels of resistance seen in clinics (2-4-fold) and are more closely than laboratory-induced cisplatin resistant cell lines (which are in the order of 10-1000-fold) [97]. In this experiment curcumin inhibited the production of interleukin IL- 6 in CAOV3 cells suggesting that one of the possible mechanisms for synergy between cisplatin and curcumin was related to decrease autologous production of IL-6. However, such synergy was also observed in the SKOV3 cell line (exerting low IL-6 expression) indicating that this action was most probably a result of multiple targeting [51]

A complex study by Montopoli et al. [98] confirmed curcumin cytotoxic activity in ovarian cancer cells and strongly revealed its synergistic action to cisplatin and a third generation platinum derivative drug, oxaliplatin-1R, 2R-diamnocycloexanoxalateplatinum (II) leading to an increase of cisplatin's and oxaliplatin's cytotoxicity in wild type human ovarian cancer cell line and C13 cisplatin-resistant ones when they were combined treated. It was shown that curcumin caused a concentration- and time-dependent inhibition of ovarian cancer cell viability. Its synergism with cisplatin and oxaliplatin in such action also occurred. In this study all compounds caused concentration-dependent inhibition $(0.01 \mu \mathrm{M}$ to $100 \mu \mathrm{M})$ of cell viability. The IC50 values for curcumin were $14.92 \mu \mathrm{M} ; 7.87 \mu \mathrm{M} ; 6.36$ $\mu \mathrm{M}$ after $24 \mathrm{~h}, 48 \mathrm{~h}$ and $72 \mathrm{~h}$, respectively; for cisplatin were as follows: $1.35 \mu \mathrm{M} ; 0.96 \mu \mathrm{M} ; 0.94 \mu \mathrm{M}$ after $24 \mathrm{~h}, 48 \mathrm{~h}$ and $72 \mathrm{~h}$, respectively. While for oxaliplatin following values were obtained in abovementioned time periods: $5.62 \mu \mathrm{M} ; 2.52 \mu \mathrm{M} ; 3.58 \mu \mathrm{M}$, respectively. Montopoli et al. showed that curcumin was more effective in cisplatinresistant than in cisplatin-sensitive ovarian cancer cells. Moreover, a synergistic inhibitory effect on cell viability of curcumin $(0.1 \mu \mathrm{M}$ to 1 $\mu \mathrm{M}$ ) with platinum drugs (all at concentrations: $0.1 \mu \mathrm{M}$ to $5 \mu \mathrm{M}$ ) in both, in wild type 2008 and C13 cells, was clearly visible. A curcumin alone $(0.5 \mu \mathrm{M}, 1.0 \mu \mathrm{M}, 5.0 \mu \mathrm{M})$ significantly reduced the percentage of wild type 2008 cells in G2/M phase in a concentration-dependent fashion and caused apoptosis (sub-G0), whereas in C13 cells it significantly increased numbers of cells in G0/G1 phase and reduced cells in $\mathrm{S}$ and $\mathrm{G} 2 / \mathrm{M}$, in comparison with untreated cells (with similar results after all three studied experimental periods: $24 \mathrm{~h}, 48 \mathrm{~h}, 72 \mathrm{~h}$ ). Compared to single-drug treatment, curcumin combined with cisplatin or oxaliplatin, at concentrations lower than IC50 $(0.5 \mu \mathrm{M}$ for all three), caused the best dose- and time-dependent increases in cellcycle arrest and apoptosis. According to Montopoli et al. [98] these results suggested a crucial role for curcumin in alteration of cell-cycle parameters, when combined with platinum drugs. It was clearly indicated that concurrent treatment of curcumin with platinum drugs makes cisplatin-resistant ovarian carcinoma cells more susceptible to the action of the platinum drugs. It was also shown that in cisplatinresistant cells (compared to cisplatin-sensitive cells), higher glutathione content may be parallel to lower ROS level (used as a markers of curcumin's antioxidative potential), and that curcumin is able to cause the concentration-dependent changes of ROS or glutathione after different time of incubation (an increase of ROS after $2 \mathrm{~h}$ incubation, but increase in glutathione after $24 \mathrm{~h}$ ). Similarly, curcumin's early pro-oxidative effect (increased ROS and reduced glutathione) and late antioxidant effect (increased glutathione) have been shown by Weir et al. [99] in ovarian cancer cells and i.e. in human myeloid leukaemia cells [100]. Therefore, study by Montopoli et al. provided an evidence that curcumin is able to increase the glutathione level in both, cisplatin-sensitive and cisplatin-resistant, ovarian cancer cells, suggesting that the increased susceptibility of ovary cancer cell to combined treatment of curcumin with platinum drugs is not related to a glutathione elimination [98].

A synergism of actions between platinum drugs-cisplatin and oxaliplatin, applied in binary combination with the curcumin and anethole were also observed in three ovarian cancer cells: A2780 (wild - type), A2780 (cisR) (cisplatin-resistant) and A2780 (ZD0473R) (ZD0473 - resistant) in another experiment by Nessa et al. [101]. Both plant metabolites were able to increase intracellular levels of glutathione and glutathione-S-transferase, hence their possessed an antioxidative activity [102-104]. Although, in this study, oxaliplatin was found to be the most active and analyzed plant compoundanethole-had the lowest activity at all, it had a greater activity in the resistant cells (A2780 (cisR) and A2780 (ZD0473R)) than other compounds. The obtained results indicated that anethole was better able to induce programmed cell death i.e. apoptosis of the resistant cell lines than of the parent cell line. Moreover, applied 2/0 combinations of anethole with both cisplatin and oxaliplatin were found to be highly synergistic, indicating that pretreatment of ovarian cancer cells with the phytochemical serves to sensitize them to platinum (cisplatin and oxaliplatin) action. Similar effects were observed in the case of curcumin. The role of NF- $\mathrm{BB}$ as a potential molecular target in the action of studied plant-origin compounds was strongly postulated by authors and others [105]. The enhanced cell kill resulting from treatment of cancer cells with these two phytochemicals (applied 2/0 sequence of administration) may be related to the reduced expression of NF- $\mathrm{KB}$ and down-regulation of AKT kinase and cyclooxygenase-2 (COX2) protein pathways. It was therefore stated that bolus addition of platinum drugs and the selected phytochemicals leading to change from agonistic to antagonistic in action may suggest that concurrent administration of these two compounds in some cases may cause failure of sensitize the ovarian cancer cells to platinum action, perhaps due to less significant reduction in the expression of NF- $\kappa B$ [50]. Thus, the prior treatment of ovarian cancer cells with anethole and curcumin appeared to be the critical determinant in lowering the expression of NF- $\kappa \mathrm{B}$ [101]. The observed action of anethole promoting cell survival at a lower concentration $(0.2 \mu \mathrm{M})$ and promoting cell death at higher concentrations $(25 \mu \mathrm{M})$ seemed to support such thesis [101].

\section{Conclusions}

Upon basic studies in this paper we have summarized available evidences of inhibitory activities of several often studied plant-origin bio-active compounds (mostly quercetin and curcumin) of ovarian cancer cells proliferation, their mechanisms of action (relying i.e. on suppression of signal transduction activity of several cellular kinases [37,47-49,60,75], induction of apoptosis [52,58], cell cycle arrest $[37,55,59])$ induction of ER stress activating protective autophagy via the p-STAT3/Bcl-2 axis [78], as well as their strong potential to sensitization of ovarian cancer cells to the presence of several platinum-based cytostatics (cisplatin and oxaliplatin) [75] and others.

Up to date several dietary, clinical (cohort and case-control) studies evaluating the association of some flavonoids (mostly nonisoflavones) and its subgroup components consumption and ovarian cancer risk were already performed (Mohammadi et al. [32], Parvaresh et al. [33], Hua et al. [6]). According to the researchers, there has been no association between ovarian cancer risk and total nonisoflavone flavonoids intake [32]. Although, some studies reported an inverse 
Citation: Kujawski R, Baraniak J, Ozarowski M, Kujawska M, Borowska M, et al. (2017) Basic Studies on Chemopreventive Properties of Quercetin and Curcumin and Other Plant-origin Compounds in Ovarian Cancer Cells - A Mini-review. Altern Integr Med 6: 238. doi: $10.4172 / 2327-5162.1000238$

Page 8 of 10

association between certain nonisoflavone flavonoids subclasses (flavonols) $[106,107]$ or other individual flavonoids (i.e. kaempferol and luteolin [107] and apigenin [108]) and ovarian cancer risk, there is a still an insufficient amount of data designed to explain the effect of quercetin or curcumin (alone or together) on ovarian cancer development and/or its chemotherapy. According to Mohammadi et al. [32] these results provide limited support for an association between nonisoflavone flavonoids intake and ovarian cancer risk; therefore there is a need for further and more accurate researches to be confirmed. Thus, we are of the opinion that this paper will contribute to a better understanding of the molecular basis for positive interactions between concomitant usage of quercetin or curcumin with above-mentioned cytostatics and other bio-active agents. This work may also contribute to an increase in the number of preclinical studies or other clinical, dietary trials using these or other phenolic/alkaloid, plant-origin constituents in order to investigate efficiency and safety of pharmacotherapy of ovarian cancer patients. We hope that such point of view, presented in this paper, extended by actual state of knowledge will be helpful to find other connections between active substances like quercetin and curcumin and cytostatics depending on dose.

\section{Acknowledgement}

This publication is financed by funds allocated to the statutory activities of the Institute of Natural Fibers and Medicinal Plants and the various Departments of Poznan University of Medical Sciences.

\section{References}

1. Gallion HH, Pieretti M, DePriest PD, van Nagell JR Jr (1995) The molecular basis of ovarian cancer. Cancer 76: 1992-1997.

2. Poole EM, Konstantinopoulos PA, Terry KL (2016) Prognostic implications of reproductive and lifestyle factors in ovarian cancer. Gynecol Oncol 142: 574-587.

3. Stadel BV (1975) Letter: The etiology and prevention of ovarian cancer. Am J Obstet Gynecol 123: 772-774.

4. Schuijer M, Berns EM (2003) TP53 and ovarian cancer. Hum Mutat 21: 285-291.

5. Kim MK, Kim K, Han JY, Lim JM, Song YS (2011) Modulation of inflammatory signaling pathways by phytochemicals in ovarian cancer Genes Nutr 6: 109-115.

6. Aggarwal BB, Shishodia S (2006) Molecular targets of dietary agents for prevention and therapy of cancer. Biochem Pharmacol 71: 1397-1421.

7. Hong WK, Sporn MB (1997) Recent advances in chemoprevention of cancer. Science 278: 1073-1077.

8. Crane TE, Khulpateea BR, Alberts DS, Basen-Engquist K, Thomson CA (2014) Dietary intake and ovarian cancer risk: a systematic review. Cancer Epidemiol Biomarkers Prev 23: 255-273.

9. Hua X, Yu L, You R, Yang Y, Liao J, et al. (2016) Association among dietary flavonoids, flavonoid subclasses and ovarian cancer risk: A MetaAnalysis. PLoS One 11: e0151134.

10. Key TJ, Schatzkin A, Willett WC, Allen NE, Spencer EA, et al. (2004) Diet, nutrition and the prevention of cancer. Public Health Nutr 7: 187-200.

11. Lewandowska H, Kalinowska M, Lewandowski W, St pkowski TM, Brazska K3 (2016) The role of natural polyphenols in cell signaling and cytoprotection against cancer development. J Nutr Biochem 32: 1-19.

12. Cassidy A, Huang T, Rice MS, Rimm EB, Tworoger SS (2014) Intake of dietary flavonoids and risk of epithelial ovarian cancer. Am J Clin Nutr 100: 1344-1351.

13. Kandaswami C, Lee LT, Lee PP, Hwang JJ, Ke FC, et al. (2005) The antitumor activities of flavonoids. In Vivo 19: 895-909.
14. Corcoran MP, McKay DL, Blumberg JB (2012) Flavonoid basics: Chemistry, sources, mechanisms of action, and safety. J Nutr Gerontol Geriatr 31: 176-189.

15. D'Archivio M, Filesi C, Di Benedetto R, Gargiulo R, Giovannini C, et al. (2007) Polyphenols, dietary sources and bioavailability. Ann Ist Super Sanita 43: 348-361.

16. U.S. Department of Agriculture (2003) USDA database for the flavonoid content of selected foods. Beltsville, Maryland 20705: 1-77.

17. Gates MA, Tworoger SS, Hecht JL, De Vivo I, Rosner B, et al. (2007) A prospective study of dietary flavonoid intake and incidence of epithelial ovarian cancer. Int J Cancer 121: 2225-2232.

18. McCann SE, Freudenheim JL, Marshall JR, Graham S (2003) Risk of human ovarian cancer is related to dietary intake of selected nutrients, phytochemicals and food groups. J Nutr 133: 1937-1942.

19. Ko EY, Nile SH, Sharma K, Li GH, Park SW (2015) Effect of different exposed lights on quercetin and quercetin glucoside content in onion (Allium cepa L.). Saudi J Biol Sci 22: 398-403.

20. Koh E, Wimalasiri K, Chassy A, Mitchell A (2009) Content of ascorbic acid, quercetin, kaempferol and total phenolics in commercial broccoli. J Food Comp Anal 22: 637-643.

21. Sun T, Xu Z, Wu CT, Janes M, Prinyawiwatkul W, et al. (2007) Antioxidant activities of different colored sweet bell peppers (Capsicum annuum L.). J Food Sci 72: S98-102.

22. Francesca N, Barbera M, Martorana A, Saiano F, Gaglio R, et al. (2016) Optimised method for the analysis of phenolic compounds from caper (Capparis spinosa L.) berries and monitoring of their changes during fermentation. Food Chem 196: 1172-1179.

23. Zielinski AAF, Alberti A, Braga CM, da Silva KM, Canteri MHG, et al. (2014) Effect of mash maceration and ripening stage of apples on phenolic compounds and antioxidant power of cloudy juices: A study using chemometrics. LWT-Food Sci Technol 57: 223-229.

24. Jeszka-Skowron M, Krawczyk M, Zgola-Grzeskowiak A (2015) Determination of antioxidant activity, rutin, quercetin, phenolic acids and trace elements in tea infusions: Influence of citric acid addition on extraction of metals. J Food Comp Anal 40: 70-77.

25. Martelo-Vidal MJ, Vázquez M (2014) Determination of polyphenolic compounds of red wines by UV-VIS-NIR spectroscopy and chemometrics tools. Food Chem 158: 28-34.

26. Kelly GS (2011) Quercetin. Monograph. Altern Med Rev 16: 172-194.

27. Maalik A, Khan FA, Mumtaz A, Mehmood A, Azhar S, et al. (2014) Pharmacological Applications of Quercetin and its Derivatives: A Short Review. Tropical J Pharmaceutical Res 13: 1561-1566.

28. Nam JS, Sharma AR, Nguyen LT, Chakraborty C, Sharma G, et al. (2016) Application of Bioactive Quercetin in Oncotherapy: From Nutrition to Nanomedicine. Molecules 21: E108.

29. Terlikowska KM, Witkowska AM, Zujko ME, Dobrzycka B, Terlikowski SJ, et al. (2014) Potential application of curcumin and its analogues in the treatment strategy of patients with primary epithelial ovarian cancer. Int J Mol Sci 15: 21703-21722.

30. Vallianou NG, Evangelopoulos A, Schizas N, Kazazis C (2015) Potential anticancer properties and mechanisms of action of curcumin. Anticancer Res 35: 645-651.

31. Chen SS, Michael A, Butler-Manuel SA (2012) Advances in the treatment of ovarian cancer: A potential role of antiinflammatory phytochemicals. Discov Med 13: 7-17.

32. Mohammadi V, Dehghani S, Larijani B, Azadbakht L (2016) Ovarian cancer risk and nonisoflavone flavonoids intake: A systematic review of epidemiological studies. J Res Med Sci 21: 123.

33. Parvaresh A, Razavi R, Rafie N, Ghiasvand R, Pourmasoumi M, et al. (2016) Quercetin and ovarian cancer: An evaluation based on a systematic review. J Res Med Sci 21: 34.

34. Niedzwiecki A, Roomi MW, Kalinovsky T, Rath M (2016) Anticancer Efficacy of Polyphenols and Their Combinations. Nutrients 8: E552. 
Citation: Kujawski R, Baraniak J, Ozarowski M, Kujawska M, Borowska M, et al. (2017) Basic Studies on Chemopreventive Properties of Quercetin and Curcumin and Other Plant-origin Compounds in Ovarian Cancer Cells - A Mini-review. Altern Integr Med 6: 238. doi: $10.4172 / 2327-5162.1000238$

Page 9 of 10

35. Scambia G, Ranelletti FO, Panici BP, Bonanno G, De Vincenzo R, et al. (1990) Synergistic antiproliferative activity of quercetin and cisplatin on ovarian cancer cell growth. Anticancer Drugs 1: 45-48.

36. Scambia G, Ranelletti FO, Panici BP, Piantelli M, Bonanno G, et al. (1992) Inhibitory effect of quercetin on primary ovarian and endometria cancers and synergistic activity with cis-diamminedichloroplatinum (II). Gynecol Oncol 45: 13-19.

37. Prajda N, Singhal RL, Yeh YA, Olah E, Look KY, et al. (1995) Linkage of reduction in 1-phosphatidylinositol 4-kinase activity and inositol, 5trisphosphate concentration in human ovarian carcinoma cells treated with quercetin. Life Sci 56: 1587-1593.

38. Hedelin M, Lof M, Andersson TM, Adlercreutz H, Weiderpass E (2011) Dietary phytoestrogens and the risk of ovarian cancer in the women's lifestyle and health cohort study. Cancer Epidemiol, Biomarkers Prev 20: 308-317.

39. Lee JY, Kim HS, Song YS (2012) Genistein as a Potential Anticancer Agent against Ovarian Cancer. J Tradit Complement Med 2: 96-104.

40. Li Y, Mi C (2003) Proliferation inhibition and apoptosis onset in human ovarian carcinoma cell line SKOV3 induced by Genistein. Ai Zheng 22: 586-591.

41. Myung SK, Ju W, Choi HJ, Kim SC (2009) Soy intake and risk of endocrine-related gynaecological cancer: A meta-analysis. British J Obstet Gyn 116: 1697-1705.

42. Sarkar FH, Li Y (2003) Soy isoflavones and cancer prevention. Cancer Invest 21: 744-757.

43. Solomon LA, Ali S, Banerjee S, Munkarah AR, Morris RT, et al. (2008) Sensitization of ovarian cancer cells to cisplatin by genistein: The role of NF-kappaB. J Ovarian Res 1: 9.

44. Wang X, Xin XY, Huang YH (2006) Regulative effect of genistein on xenografted tumor of ovarian carcinoma cell on nude mice. Zhongguo Zhong Yao Za Zhi 31: 901-904.

45. Li Y, Che M, Bhagat S, Ellis KL, Kucuk O, et al. (2004) Regulation of gene expression and inhibition of experimental prostate cancer bone metastasis by dietary genistein. Neoplasia 6: 354-363.

46. Tatsuta M, Iishi H, Baba M, Yano H, Uehara H, et al. (1990) Attenuation by genistein of sodium-chloride-enhanced gastric carcinogenesis induced by $\mathrm{N}$-methyl-N'-nitro-Nnitrosoguanidine in Wistar rats. Int J Cancer 80: 396-399.

47. Shen F, Weber G (1997) Synergistic action of quercetin and genistein in human ovarian carcinoma cells. Oncol Res 9: 597-602.

48. Li W, Shen F, Weber G (1999) Ribavirin and quercetin synergistically downregulate signal transduction and are cytotoxic in human ovarian carcinoma cells. Oncol Res 11: 243-247.

49. Weber G, Shen DF, Li W, Yang H, Look KY, et al. (2000) Signal transduction and biochemical targeting of ovarian carcinoma. Eur J Gynaecol Oncol 21: 231-236.

50. Nessa MU, Beale P, Chan C, Yu JQ, Huq F (2011) Synergism from combinations of cisplatin and oxaliplatin with quercetin and thymoquinone in human ovarian tumour models. Anticancer Res 31: 3789-3797.

51. Chan MM, Fong D, Soprano KJ, Holmes WF, Heverling H (2003) Inhibition of growth and sensitization to cisplatin-mediated killing of ovarian cancer cells by polyphenolic chemopreventive agents. J Cell Physiol 194: 63-70.

52. Gao X, Wang B, Wei X, Men K, Zheng F, et al. (2012) Anticancer effect and mechanism of polymer micelle-encapsulated quercetin on ovarian cancer. Nanoscale 4: 7021-7030.

53. Maciejczyk A, Surowiak P (2013) Quercetin inhibits proliferation and increases sensitivity of ovarian cancer cells to cisplatin and paclitaxel. Ginekol Pol 84: 590-595.

54. Catanzaro D, Vianello C, Ragazzi E, Caparrotta L, Montopoli M (2014) Cell cycle control by natural phenols in cisplatin-resistant cell lines. Nat Prod Commun 9: 1465-1468.

55. Catanzaro D, Ragazzi E, Vianello C, Caparrotta L, Montopoli M (2015) Effect of quercetin on cell cycle and cyclin expression in ovarian carcinoma and osteosarcoma cell lines. Nat Prod Commun 10: 1365-1368.

56. Kurbanov BM, Fecker LF, Geilen CC, Sterry W, Eberle J (2007) Resistance of melanoma cells to TRAIL does not result from upregulation of antiapoptotic proteins by NFkappaB but is related to downregulation of initiator caspases and DR4. Oncogene 26: 3364-3377.

57. van Geelen CM, Pennarun B, Le PT, de Vries EG, de Jong S (2011) Modulation of TRAIL resistance in colon carcinoma cells: Different contributions of DR4 and DR5. BMC Cancer 11: 39.

58. Yi L, Zongyuan Y, Cheng G, Lingyun Z, Guilian Y, et al. (2014) Quercetin enhances apoptotic effect of tumor necrosis factor-related apoptosisinducing ligand (TRAIL) in ovarian cancer cells through reactive oxygen species (ROS) mediated CCAAT enhancer-binding protein homologous protein (CHOP)-death receptor 5 pathway. Cancer Sci 105: 520-527.

59. Ren MX, Deng XH, Ai F, Yuan GY, Song HY (2015) Effect of quercetin on the proliferation of the human ovarian cancer cell line SKOV-3 in vitro. Exp Ther Med 10: 579-583.

60. Yang Z, Liu Y, Liao J, Gong C, Sun C, et al. (2015) Quercetin induces endoplasmic reticulum stress to enhance cDDP cytotoxicity in ovarian cancer: involvement of STAT3 signaling. FEBS J 282: 1111-1125.

61. Michaud-Levesque J, Bousquet-Gagnon N, Beliveau R (2012) Quercetin abrogates IL-6/STAT3 signaling and inhibits glioblastoma cell line growth and migration. Exp Cell Res 318: 925-935.

62. Sheng WJ, Jiang $\mathrm{H}$, Wu DL, Zheng JH. Early responses of the STAT3 pathway to platinum drugs are associated with cisplatin resistance in epithelial ovarian cancer. Braz J Med Biol Res 46: 650-658.

63. Li W, Liu M, Xu YF, Feng Y, Che JP, et al. (2014) Combination of quercetin and hyperoside has anticancer effects on renal cancer cells through inhibition of oncogenic microRNA-27a. Oncol Rep 31: 117-124.

64. Zhou J, Gong J, Ding C, Chen G (2015) Quercetin induces the apoptosis of human ovarian carcinoma cells by upregulating the expression of microRNA-145. Mol Med Rep 12: 3127-3131.

65. Wu H, Xiao Z, Wang K, Liu W, Hao Q (2013) MiR-145 is downregulated in human ovarian cancer and modulates cell growth and invasion by targeting p70S6K1 and MUC1. Biochem Biophys Res Commun 441: 693-700.

66. Zhang S, Lu Z, Unruh AK, Ivan C, Baggerly KA, et al. (2015) Clinically relevant microRNAs in ovarian cancer. Mol Cancer Res 13: 393-401.

67. Tao SF, He HF, Chen Q (2015) Quercetin inhibits proliferation and invasion acts by up-regulating miR-146a in human breast cancer cells. Mol Cell Biochem 402: 93-100.

68. Zhang X, Guo Q, Chen J, Chen Z (2015) Quercetin enhances cisplatin sensitivity of human osteosarcoma cells by modulating microRNA-217KRAS axis. Mol Cells 38: 638-642.

69. Clem B, Telang S, Clem A, Yalcin A, Meier J, et al. (2008) Small-molecule inhibition of 6-phosphofructo-2-kinase activity suppresses glycolytic flux and tumor growth. Molecular Cancer Therapeutics 7: 110-120.

70. Xintaropoulou C, Ward C, Wise A, Marston H, Turnbull A, et al. (2015) A comparative analysis of inhibitors of the glycolysis pathway in breast and ovarian cancer cell line models. Oncotarget 6: 25677-25695.

71. Hanahan D, Weinberg RA (2011) Hallmarks of cancer: The next generation. Cell 144: 646-674.

72. Tennant DA, Durán RV, Gottlieb E (2010) Targeting metabolic transformation for cancer therapy. Nat Rev Cancer 10: 267-277.

73. Zhao Y, Butler EB, Tan M (2013) Targeting cellular metabolism to improve cancer therapeutics. Cell Death Dis 4: e532.

74. Wang Y, Han A, Chen E, Singh RK, Chichester CO, et al. (2015) The cranberry flavonoids PAC DP-9 and quercetin aglycone induce cytotoxicity and cell cycle arrest and increase cisplatin sensitivity in ovarian cancer cells. Int J Oncol 46: 1924-1934.

75. Kim MK, Choi HS, Cho SG, Shin YC, Ko SG (2016) Rubus coreanus Miquel extract causes apoptosis of doxorubicin-resistant NCI/ADR-RES ovarian cancer cells via JNK phosphorylation. Mol Med Rep 13: 4065-4072. 
Citation: Kujawski R, Baraniak J, Ozarowski M, Kujawska M, Borowska M, et al. (2017) Basic Studies on Chemopreventive Properties of Quercetin and Curcumin and Other Plant-origin Compounds in Ovarian Cancer Cells - A Mini-review. Altern Integr Med 6: 238. doi: $10.4172 / 2327-5162.1000238$

Page 10 of 10

76. Choi HS, Kim MK, Choi YK, Shin YC, Cho SG, et al. (2016) Rhus verniciflua Stokes (RVS) and butein induce apoptosis of paclitaxelresistant SKOV-3/PAX ovarian cancer cells through inhibition of AKT phosphorylation. BMC Complement Altern Med 16: 122.

77. Ediriweera MK, Tennekoon KH, Adhikari A, Samarakoon SR, Thabrew I, et al. (2016) New halogenated constituents from Mangifera zeylanica Hook.f. and their potential anti-cancer effects in breast and ovarian cancer cells. J Ethnopharmacol 189: 165-174.

78. Liu Y, Gong W, Yang ZY, Zhou XS, Gong C, et al. (2017) Quercetin induces protective autophagy and apoptosis through ER stress via the $\mathrm{p}$ STAT3/Bcl-2 axis in ovarian cancer. Apoptosis 22: 544-557.

79. Zhou Y, Liang X, Chang H, Shu f, Wu Y, et al. (2014) Ampelopsininduced autophagy protects breast cancer cells from apoptosis through Akt-mTOR pathway via endoplasmic reticulum stress. Cancer Sci 105: 1279-1287.

80. Wang K, Liu R, Li J, Mao J, Lei Y, et al. (2011) Quercetin induces protective autophagy in gastric cancer cells: involvement of Akt-mTOR and hypoxia-induced factor lalpha-mediated signaling. Autophagy 7: 966-978.

81. De A, De A, Papasian C, Hentges S, Banerjee S, et al. (2013) Emblica officinalis extract induces autophagy and inhibits human ovarian cancer cell proliferation, angiogenesis, growth of mouse xenograft tumors. PLoS One 8: e72748.

82. Roomi MW, Ivanov V, Kalinovsky T, Niedzwiecki A, Rath M (2006) Inhibition of matrix metalloproteinase-2 and invasion of human ovarian cancer cell SK-OV-3 with lysine, proline, arginine, ascorbic acid and green tea extract. J Obstet Gynaecol Res 32: 148-154.

83. Ahmad KA, Harris NH, Johnson AD, Lindvall HC, Wang G, et al. (2007) Protein kinase CK2 modulates apoptosis induced by resveratrol and epigallocatechin gallate in prostate cancer cells. Mol Cancer Ther 6: 1006-1012.

84. Hsieh TC, Wu JM (2008) Suppression of cell proliferation and gene expression by combinatorial synergy of EGCG, resveratrol and gammatocotrienol in estrogen receptor-positive MCF-7 breast cancer cells. Int J Oncol 33: 851-859.

85. Hsieh TC, Wu JM (2009) Targeting CWR22Rv1 prostate cancer cell proliferation and gene expression by combinations of the phytochemicals EGCG, genistein and quercetin. Anticancer Res 29: 4025-4032.

86. Saha A, Kuzuhara T, Echigo N, Suganuma M, Fujiki H (2010) New role of (-)-epicatechin in enhancing the induction of growth inhibition and apoptosis in human lung cancer cells by curcumin. Cancer Prev Res (Phila) 3: 953-962.

87. Tang SN, Singh C, Nall D, Meeker D, Shankar S, et al. (2010) The dietary bioflavonoid quercetin synergizes with epigallocatechin gallate (EGCG) to inhibit prostate cancer stem cell characterstic, invasion migration and epithelial-mesenchymal transition. J Mol Signal 5: 14.

88. Niedzwiecki A, Roomi MW, Kalinovsky T, Rath M (2010) Micronutrient synergy--a new tool in effective control of metastasis and other key mechanisms of cancer. Cancer Metastasis Rev 29: 529-542.

89. Zhou DH, Wang X, Yang M, Shi X, Huang W, et al. (2013) Combination of low concentration of (-)epigallocatechin gallate (EGCG) and curcumin strongly suppresses the growth of non-small cell lung cancer in vitro and in vivo through causing cell cycle arrest. Int J Mol Sci 14: 12023-12036.

90. Williamson G, Manach C (2005) Bioavailability and bio efficacy of polyphenols in humans. II. Review of 93 intervention studies. Am J Clin Nutr 81: 243S-255S.

91. Roomi MW, Kalinovsky T, Rath M, Niedzwiecki A (2016) A nutrient mixture modulates ovarian ES-2 cancer progression by inhibiting xenograft tumor growth and cellular MMP secretion, migration and invasion. Int J Clin Exp Med 9: 814-822.

92. Roomi MW, Niedzwiecki A, Rath M (2016) Abstract 4053: A unique nutrient mixture suppresses ovarian cancer growth of A-2780 by inhibiting invasion and MMP-9 secretion. In Proceedings of the 107th Annual Meeting of the AACR, New Orleans, LA, USA.

93. Roomi MW, Kalinovsky T, Rath M, Niedzwiecki A (2017) A specific mixture of nutrients suppresses ovarian cancer a-2780 tumor incidence, growth, and metastasis to lungs. Nutrients 9: E303.

94. Davidson B, Goldberg I, Gotlieb WH, Kopolovic J, Ben-Baruch G, et al. (1999) High levels of MMP-, MMP-9, MT1-MMP and TIMP-2 mRNA correlate with poor survival in ovarian carcinoma. Clin Exp Metastasis 17: 799-808.

95. Davidson B, Goldberg I, Gotlieb WH, Kopolovic J, Ben-Baruch G, et al. (2002) The prognostic value of metalloproteinases and angiogenic factors in ovarian carcinoma. Mol Cell Endocrinol 187: 39-45.

96. Wu X, Li H, Kang L, Li L, Wang W, et al. (2002) Activated matrix metalloproteinase-2a potential marker of prognosis for epithelial ovarian cancer. Gynecol Oncol 84: 126-134.

97. Trimmer EE, Essigmann JM (1999) Cisplatin. Essays Biochem 34: 191-211.

98. Montopoli M, Ragazzi E, Froldi G, Caparrotta L (2009) Cell-cycle inhibition and apoptosis induced by curcumin and cisplatin or oxaliplatin in human ovarian carcinoma cells. Cell Prolif 42: 195-206.

99. Weir NM, Selvendiran K, Kutala VK, Tong L, Vishwanath S, et al. (2007) Curcumin induces $\mathrm{G} 2 / \mathrm{M}$ arrest and apoptosis in cisplatin-resistant human ovarian cancer cells by modulating Akt and p38 MAPK. Cancer Biol Ther 6: 178-184.

100. Sandur SK, Ichikawa H, Pandey MK, Kunnumakkara AB, Sung B, et al. (2007) Role of pro-oxidants and antioxidants in the anti-inflammatory and apoptotic effects of curcumin (diferuloylmethane). Free Radic Biol Med 43: 568-580.

101. Nessa MU, Beale P, Chan C, Yu JQ, Huq F (2012) Studies on combination of platinum drugs cisplatin and oxaliplatin with phytochemicals anethole and curcumin in ovarian tumour models. Anticancer Res 32: 4843-4850.

102. Bouthillier L, Charbonneau M, Brodeur J (1996) Assessment of the role of glutathione conjugation in the protection afforded by anethol dithiolthione against hexachloro-,3-butadiene-induced nephrotoxicity. Toxicol Appl Pharmacol 139: 177-185.

103. Chen CH, deGraffenried LA (2012) Anethole suppressed cell survival and induced apoptosis in human breast cancer cells independent of estrogen receptor status. Phytomedicine 19: 763-767.

104. Drukarch B, Schepens E, Stoof JC, Langeveld CH (1997) Anethole dithiolethione prevents oxidative damage in glutathione-depleted astrocytes. Eur Pharmacol 329: 259-262.

105. Banerjee S, Padhye S, Azmi A, Wang Z, Philip PA, et al. (2010) Review on molecular and therapeutic potential of thymoquinone in cancer. Nutr Cancer 62: 938-946.

106. Rossi M, Bosetti C, Negri E, Lagiou P, La Vecchia C (2010) Flavonoids, proanthocyanidins, and cancer risk: a network of case-control studies from Italy. Nutr Cancer 62: 871-877.

107. Rossi M, Negri E, Lagiou P, Talamini R, Dal Maso L, et al. (2008) Flavonoids and ovarian cancer risk: A case-control study in Italy. Int J Cancer 123: 895-898.

108. Gates MA, Vitonis AF, Tworoger SS, Rosner B, Titus-Ernstoff L, et al. (2009) Flavonoid intake and ovarian cancer risk in a population-based case-control study. Int J Cancer 124: 1918-1925. 